\title{
Profound connotations of parameters on the geometric anisotropy of pores in which oil store and flow: A new detailed case study which aimed to dissect, conclude and improve the theoretical meaning and practicability of "Umbrella Deconstruction" method furtherly
}

\author{
Shuheng Du \\ State Key Laboratory of Nonlinear Mechanics, Institute of Mechanics, Chinese Academy of Sciences, No. 15, Beisihuanxi Road, Beijing, 100190, China
}

\section{A R T I C L E I N F O}

\section{Article history:}

Received 20 February 2020

Received in revised form 3 June 2020

Accepted 13 August 2020

Available online 25 August 2020

\section{Keywords:}

Unconventional hydrocarbon

Anisotropy

"Umbrella deconstruction"

Reservoir characterization

Pore geometry

\begin{abstract}
A B S T R A C T
"Umbrella Deconstruction" method has already been raised in a set of published papers accomplished by the author of this study and his collaborators. This method aimed to unlock the "black box" of the anisotropic pores, elements and minerals of reservoirs from a new perspective. Compared with all the previous case studies, the purpose of this study is to investigate the profound connotations and special significance of the geometric parameters describing the pores in the study of "Umbrella Deconstruction" method furtherly.

This new case study shows the extreme points of reservoir properties could be the turning points of some complex geological processes. It also shows that there are two possible mechanisms which would control the geometry of the pore boundary, including "the differential corrosion due to compaction process" and "the seepage process controlled by dominant channels". The location of the maximum and minimum values of eight sections and the angle between the maximum and minimum values had significance in the geologic mechanism and development processes.

The conclusions suggest that, when we carry out the study of micro-anisotropy characterization, we should investigate what relative quantitative enlightenment can be brought to us by the change characteristics and laws of pore geometry parameters from both the geological and engineering perspectives. This will contribute to the further explanation and improvement of the practicability of "Umbrella Deconstruction" in pore characterization.
\end{abstract}

(๑) 2020 Elsevier Ltd. All rights reserved.

\section{Introduction}

Studies of natural and social sciences on the topic of "energy" are of great significance. In response to this major problem, scholars of geology, mechanics and other disciplines have paid great attention to and made many predictions [1-4]. For example, some scholars have proposed prediction models of oil and gas production and power consumption respectively by means of trend analysis or genetic algorithm [5,6]. With the continuous use of fossil energy and the emission of carbon dioxide, the greenhouse effect on the earth is gradually prominent. Some scholars even point out that new energy management can use the greenhouse effect to reverse the situation and produce renewable energy [7]. Thus, different

E-mail address: dushuheng@imech.ac.cn. scholars have different views on energy use and consumption.

According to "[8]", global energy demand grew by $2.9 \%$ and carbon emissions grew by $2.0 \%$ in 2018 , natural gas consumption and production was up over $5 \%$, Renewables grew by $14.5 \%$, and coal consumption $(+1.4 \%)$ and production $(+4.3 \%)$ increased for the second year in a row in 2018. China accounted for $24 \%$ of global energy consumption and $34 \%$ of global energy consumption growth in 2018. As to the fossil fuel consumption in China, consumption growth was led by natural gas $(+18 \%)$ and oil $(+5.0 \%)$, while coal use rose $(+0.9 \%)$, the second consecutive year of growth。In fact, oil and gas will continue to be the main energy consumption type in China and the world for a long time.

In essence, the vast majority of fossil energy such as oil and natural gas could be found in the pores of rocks. In the characterization of reservoir pores, predecessors have done a lot of effective studies, which provides very important evidence for revealing the 
original appearance of reservoir pores. We can divide the previous studies in this field into two categories. The first kind of research is about fluid tests, including high-pressure mercury injection, constant velocity mercury injection, nuclear magnetic resonance, seepage experiment, etc. As we cannot see the real situation of fluid flowing in the reservoir, we need a lot of theoretical assumptions to help us infer the size and shape of the reservoir pores. The second kind of research is imaging tests, including a series of CT scanning, SEM, small angle scattering technology and so on [28]. The advantage of an imaging test is that we can see the morphology of pores more truly. With the popularity of unconventional oil and gas reservoir research, the direction of scholars' efforts mostly lies in how to see the smaller and smaller pores. This will undoubtedly make us ignore the significance of taking into account both sample size (Scale) and resolution (Rev) for pore heterogeneity quantification in reservoirs $[9,10]$.

Here are some representative research topics and their technical details. Like Gunde et al. [11] used high resolution micro-computed tomography (micro-CT) images of Berea sandstone core to obtain the heterogeneous pore geometry. Klaver [12] and others quantitatively estimated porosity and explored the pore space morphology of Posidonia shale (sample size $140 \mu \mathrm{m} \times 140 \mu \mathrm{m}$ with a resolution of $100 \mathrm{~nm}$ ) using the broad Ion Beam Polishing and High Resolution-SEM. Lai et al. [13] used image processing technology and a nitrogen adsorption test to explore the characteristic pore size of Berea sandstone, in which the mineral surface area distribution can be used to quantify its heterogeneity. Alyafei et al. [14] studied the accuracy differences in porosity and permeability estimations of limestone by changing the image resolution (REV). Their results showed that the change of permeability of limestone data was as low as $25 \%$, and the change of porosity was as high as $50 \%$. Lewis et al. [15] proposed a multi-dimensional NMR method to characterize the heterogeneity of pore structure. Based on the correlation of magnetic susceptibility in the multi-dimensional experiment, the heterogeneity of porous network geometry was inferred. Wang et al. [16] used fractal and multifractal methods to find that the average fractal dimension and the average width of different types of pores are different, and the degree of microheterogeneity is, in turn, intergranular pores, intragranular pores, and organic pores. Huang [17] believes that the fractal dimension of micro-scale space increases gradually, while the fractal dimension of nano-scale space decreases. This indicates that as the heterogeneity of micro-scale space increases gradually, the nano-scale space weakens gradually. Jin et al. [18] used the high-pressure mercury injection tests to show that pore throat radii are less than $10 \mathrm{~nm}$ for most pores in the heterogeneous Bakken shale. Saif et al. [19] characterized the microstructural heterogeneity of oil shale using X-ray micro-tomography $(\mu \mathrm{CT})$, automated ultra-high resolution scanning electron microscopy (SEM), MAPS Mineralogy (Modular Automated Processing System) and Focused Ion Beam Scanning Electron Microscopy (FIB-SEM). Munawar et al. [20] suggested that the success of the pore network model (PNM) in predicting the physical properties of rocks depends on three factors: image segmentation, image resolution, and rock homogeneity. They also indicate belief that the single-scale PNM method cannot solve the problem of the fine characterization of tight reservoir rocks, so it is necessary to explore multi-scale characterization methods. Sun [21] and others used the eigenvalues and eigenvectors of permeability tensors to quantitatively characterize the nanoporous heterogeneity of gas shale based on synchrotron radiation nano-CT technology.

"Umbrella Deconstruction" method mentioned in the title of this paper has a clear development process. Du et al. [22] firstly proposed the concept of "Umbrella Deconstruction" to characterize the pore heterogeneity and anisotropy of unconventional reservoirs in relative large scale by combining the advanced imaging techniques, which could reduce the contradiction between observation resolution and scale to a certain extent. It can be seen from Du et al. [22] that the concept of "Umbrella Deconstruction" was originally proposed to solve the technical problem of precise description of pore anisotropy and heterogeneity. This paper also became the beginning of all the studies on "Umbrella Deconstruction".

At almost the same time point, based on the research of Du et al. [22], Du et al. [23] broadened the application scope of "Umbrella Deconstruction" for the first time. A kind of mineral named "calcite" with special geological and engineering significance is identified by combining the point measurement of Energy Dispersive Spectrometer (EDS). It's all because the content and distribution characteristics of calcite directly affect the brittleness and fracturing ability of rock. We can capture enough number of calcite in eight directions for our research through "Umbrella Deconstruction" slices. By drawing the calcite property curve of reservoir slices in eight directions, the potential and dominant direction of formation of pressure fracture can be well understood. Du et al. [23] is the first extension of "Umbrella Deconstruction" technology.

Obviously, the indicative significance of individual mineral is limited and suitable for solving a specific problem. In order to get a complete picture of the reservoir, we can start with the distribution of the overall elements of the reservoir. Based on this, Du et al. [24] and Du et al. [25] continue to broaden the testing field of EDS on the basis of [23]. Using the surface measurement of EDS, the element content distribution of "Chang 8 " reservoir samples in Jiyuan area of Ordos Basin and "Chang 7" reservoir in HJS area of China are obtained. The micro evidence of the existence of the dominant fracture area is inferred. It is worth mentioning that in the study of Du et al. [25]; the author first collected multiple synchronous samples in the same full diameter sample. By calculating the mean value of the experimental data in the same direction of the synchronous sample, the reliability of the experimental results was greatly enhanced. At the same time, Du et al. [25] also selects samples from adjacent areas for supplementary verification. This is undoubtedly a special progress compared with [9] and Du et al. [23].

In fact, since [22] first proposed the concept of "umbrella type deconstruction", this method should be widely used in the characterization of reservoir pores. Only in this way, we can continuously prove the vitality of the new method and make it continuously tested in the practice of different reservoirs. Based on this, Du et al. [26] selected the tight sandstone oil reservoir samples from Western China to carry out a preliminary case study on the characterization of pore and mineral anisotropy and heterogeneity. Compared with Du et al. [22] and Du et al. [23]; it selects the geometric parameters to describe the pores and mineral bands comprehensively, proves that there is indeed a very significant anisotropy in the pores and minerals of the reservoir in this area, and gives some obvious conclusions without further discussion. However, when the geometric parameters of each pore are applied to the characterization of micro-anisotropy, the quantitative and profound connotation of these parameters (including geological and engineering significance) still needs further consideration and excavation. In fact, the author has mentioned the practical application of the relevant fracture or pore geometric parameters in some other occasions, but this does not mean that the special significance of these geometric parameters in the study of "Umbrella Deconstruction" has been solved thoroughly. Therefore, we still need to explore furtherly [27].

In general, the purpose of this paper is to carry out a new detailed case study based on all the previous research results and the "Umbrella Deconstruction" method. This study is mainly to analyze an important issue. That is when we carry out the research 
of micro-anisotropy characterization, we need to figure out what relative quantitative enlightenment can be brought to us by the change characteristics and laws of pore geometry parameters from both the geological and engineering perspectives. This will contribute to the further explanation and improvement of the practicability of "Umbrella Deconstruction" in the characterization of reservoir spaces. This will also help readers to grasp the practical significance of "Umbrella Deconstruction" for micro reservoir characterization more clearly. Therefore, this research is timely and necessary.

\section{Methodology}

According to the technical process of "Umbrella Deconstruction" technique [22], the reservoir rock with low porosity and permeability was processed (Fig. 1). High resolution imaging of slices from eight directions was carried out with a field electronic scanning electron microscope and fine characterization was performed effectively and flexibly.

To comprehensively characterize the heterogeneity and anisotropy of reservoirs within $360^{\circ}$ (represented by eight directions of slices), several properties to quantify the pore characteristics include the average solidity, the average tortuosity, the average shape factor, the mean variance of the extension angle, and the fractal dimension. In the following text, definitions of the five properties are all explained respectively. Geological and development characteristics represented by the above properties are clarified, and the properties change curves with the change of angle were also drawn. The heterogeneous and anisotropic characteristics of pores in tight reservoirs are studied in detail.

\section{Profound connotations analysis on pore geometry anisotropy}

In classical petroleum geology, physical properties (including porosity and permeability) are the most widely used evaluation parameters. Since umbrella sections are surfaces in twodimensional space, the concepts of porosity and permeability used here are surface porosity and surface permeability.

It should be noted that the surface porosity is mainly obtained by image denoising, gray level recognition, pore extraction, and quantitative image processing. The surface permeability is calculated by combining the Darcy law and the Poiseuille equation based on the capillary bundle model. The approximate calculation formula is:
$K=\frac{\phi r^{2}}{8}$

In formula (1), “ $\phi$ " indicates the porosity and " $r$ " indicates the average pore-throat radius.

Regarding porosity findings in Fig. 2, the maximum value of the curve appeared at $0^{\circ}\left(180^{\circ} / 360^{\circ}\right)$ and the minimum value appeared at $135^{\circ}\left(315^{\circ}\right)$. With the change of angle from $0^{\circ}\left(180^{\circ} / 360^{\circ}\right)$ to $157.5^{\circ}\left(337.5^{\circ}\right)$, the overall change trend of porosity gradually decreased, with a range (ratio of maximum to minimum) of 1.62. The angle of the reservoir slice where the extreme value was located was $135^{\circ}$.

With respect to permeability, the maximum occurred at $45^{\circ}$ $\left(225^{\circ}\right)$ while the minimum occurred at $22.5^{\circ}\left(202.5^{\circ}\right)$. The angle of the reservoir slice where the extreme value was located was $22.5^{\circ}$. This shows that this kind of reservoir has the potential to form high permeability channels, and that the maximum permeability and minimum permeability are adjacent (Fig. 2).

After the highest point, the permeability decreased linearly with the change of angle. This indicates that for the reservoir sample, the permeability will change abruptly at some angle, but not in a strictly linear or stable fashion. This also provides evidence for the occurrence of remaining oil and gas in the development process, indicating that the development of compact oil and gas should still involve the study of high permeability channels.

At the same time, it can also be seen that the change trends of porosity and permeability are not consistent, and that permeability is affected by multiple factors. This also shows the complexity of tight reservoirs.

\subsection{The average pore-throat solidity}

From the perspective of sedimentary geology, a sandstone reservoir is formed by the process of accumulation, compaction, and diagenesis of mineral particles. Therefore, it is reasonable to assume that the overall concavity of the pore should be high in the reservoir with strong compaction. The average degrees of concave and convex pores can be used as indicative parameters of reservoir compaction $[27,29]$.

Quantification of these parameters is helpful in determining the degrees of reservoir compaction. However, sedimentary geology still lacks the use of micro-parameters in describing the degrees of concave and convex pores in a reservoir, which requires construction of the new parameter. The concept of "particle solidity" for the shape of particles is as followings:

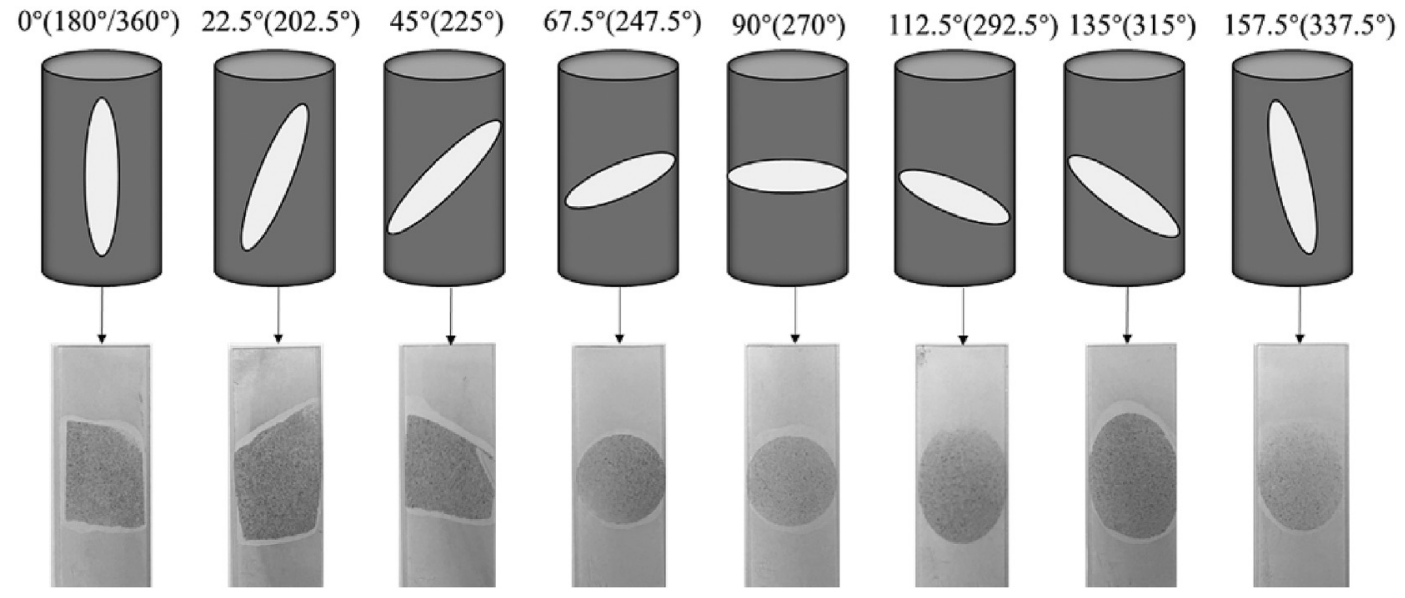

Fig. 1. Reservoir rock slices with low porosity and permeability obtained by "Umbrella Deconstruction" method. 

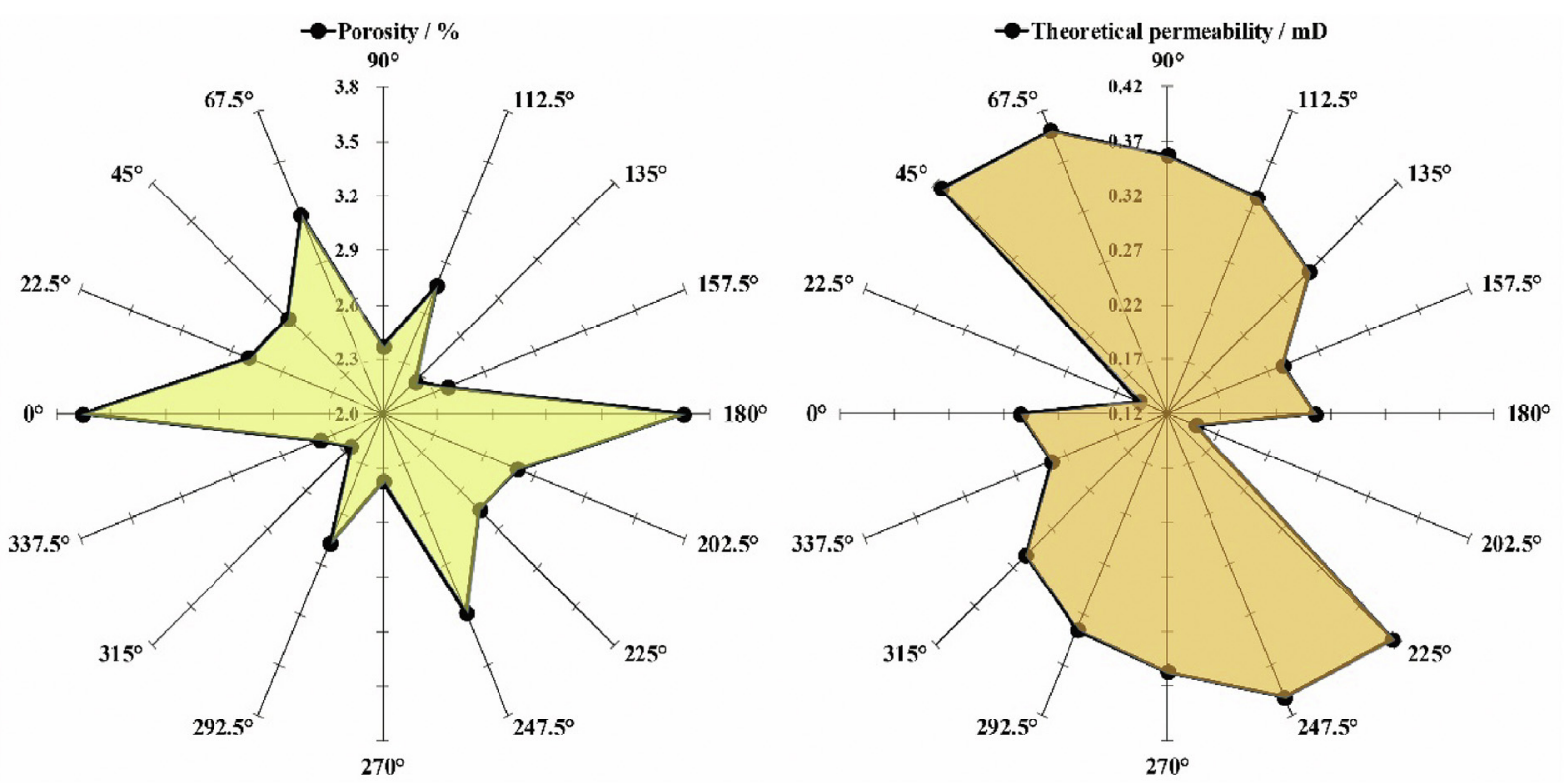

Fig. 2. The average "porosity" \& "theoretical permeability" in eight thin sections with different angles.

Solidity $=\frac{S}{S_{C}}$

In equation (2), $\mathrm{S}$ is the particle area and Sc is the area of the convex hull of the particle boundary.

Analogous to "particle solidity," the parameter of "pore-throat solidity" has been introduced which could be used to characterize the concave and convex degrees of pores. With respect to the new parameter, the "S" and "Sc" in equation (2) would be the pore area and the area of the convex hull of the pore boundary, respectively. Therefore, the smaller the pore-throat solidity, the higher the degree of compaction [27,29].

Fig. 3 shows that the maximum value of pore-throat solidity curve appeared at $67.5^{\circ}\left(247.5^{\circ}\right)$ and the minimum value appeared at $22.5^{\circ}\left(202.5^{\circ}\right)$. This shows that the compaction degree in the direction of $22.5^{\circ}\left(202.5^{\circ}\right)$ was the highest, while that in the direction of $67.5^{\circ}\left(247.5^{\circ}\right)$ was the lowest. The sharp angle of the reservoir slices where the two extreme values were located was $45^{\circ}$.

Fig. 3 also shows that the maximum value of sorting degree curve of pore-throat solidity appeared at $112.5^{\circ}\left(292.5^{\circ}\right)$, and the minimum value appeared at $90^{\circ}\left(270^{\circ}\right)$. The sharp angle of the reservoir slices where the two extreme values were located was $22.5^{\circ}$.

However, there is a question that deserves consideration. The sample size of rock slices used in this study was small. If we put it in the reservoir perspective, all the slices would bear the same compaction process, so the difference of compaction degree mainly originates from the mechanical properties of rock reservoirs represented by each slice. Specifically, different mineral particle content and pore development degrees in different directions lead to different mechanical properties in different directions. This in turn results in different deformations in different directions when the same reservoir accepts the same stress. Ultimately, it depends on the anisotropy and heterogeneity of tight reservoirs.

\subsection{The average pore-throat shape factor}

The shape factor of a pore indicates the approximate degree between the geometric shape of the individual pore and the regular circle. The higher the shape factor, the closer the geometric shape of the individual pore to the standard circle.

Fig. 4 shows that the maximum value of the shape factor appeared at $67.5^{\circ}\left(247.5^{\circ}\right)$ and the minimum value appeared at $22.5^{\circ}\left(202.5^{\circ}\right)$. This shows that the geometric shape of pores with the degree of $67.5^{\circ}\left(247.5^{\circ}\right)$ were the closest to the standard circle, while that of the pores with $22.5^{\circ}\left(202.5^{\circ}\right)$ deviated the most from the standard circle. The sharp angle of the reservoir slices where the two extreme values were located was $45^{\circ}$.

Fig. 4 also shows that the maximum uniformity (sorting degree) of the shape factor occurred at $0^{\circ}\left(180^{\circ}\right)$ and the minimum occurred at $135^{\circ}\left(315^{\circ}\right)$. The sharp angle between the two extremes was $135^{\circ}$.

\subsection{Mean variances of the extension angles}

Petroleum reservoir rocks undergo weathering, erosion, transportation, and deposition. In this process, due to directional flow, minerals can easily spread along a certain fixed direction. The directional distribution of minerals results in the directional distribution of pores.

Statistically speaking, the standard deviation (mean square deviation) of a data set can well reflect the discrete degree of a data set. The larger the standard deviation, the greater the discrete degree of the data set and the more unstable the data change. On the contrary, the smaller the discrete degree of the data set, the more stable the data value. When this parameter was applied to our research, we found that if we could get the standard deviation of all extension angles of the pores, we could measure the degrees of pore orientation by taking single direction reservoir slices as the research object. The smaller the standard deviation of extension angle, the better the orientation of reservoir slices in this direction. Finally, we could evaluate the problem of dominant seepage channels by comparing the degree of directionality in different directions.

Therefore, we took the slice in a single direction as the research object, and did so for slices in all directions. The Legendre ellipse fitting was carried out for all pores in a single slice. With the Cartesian coordinate system as the standard, the extension angle of the 

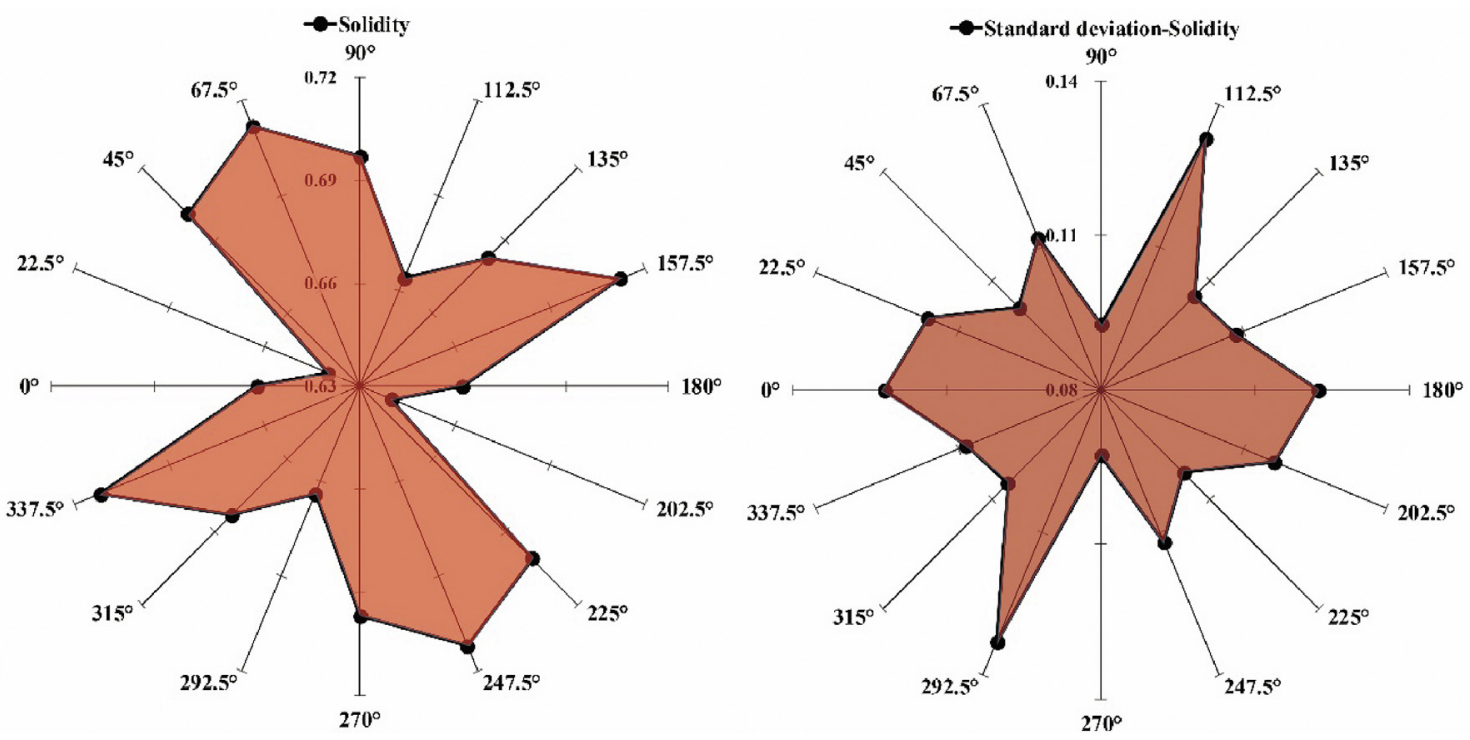

Fig. 3. The average and standard deviation of "solidity" in eight thin sections with different angles.

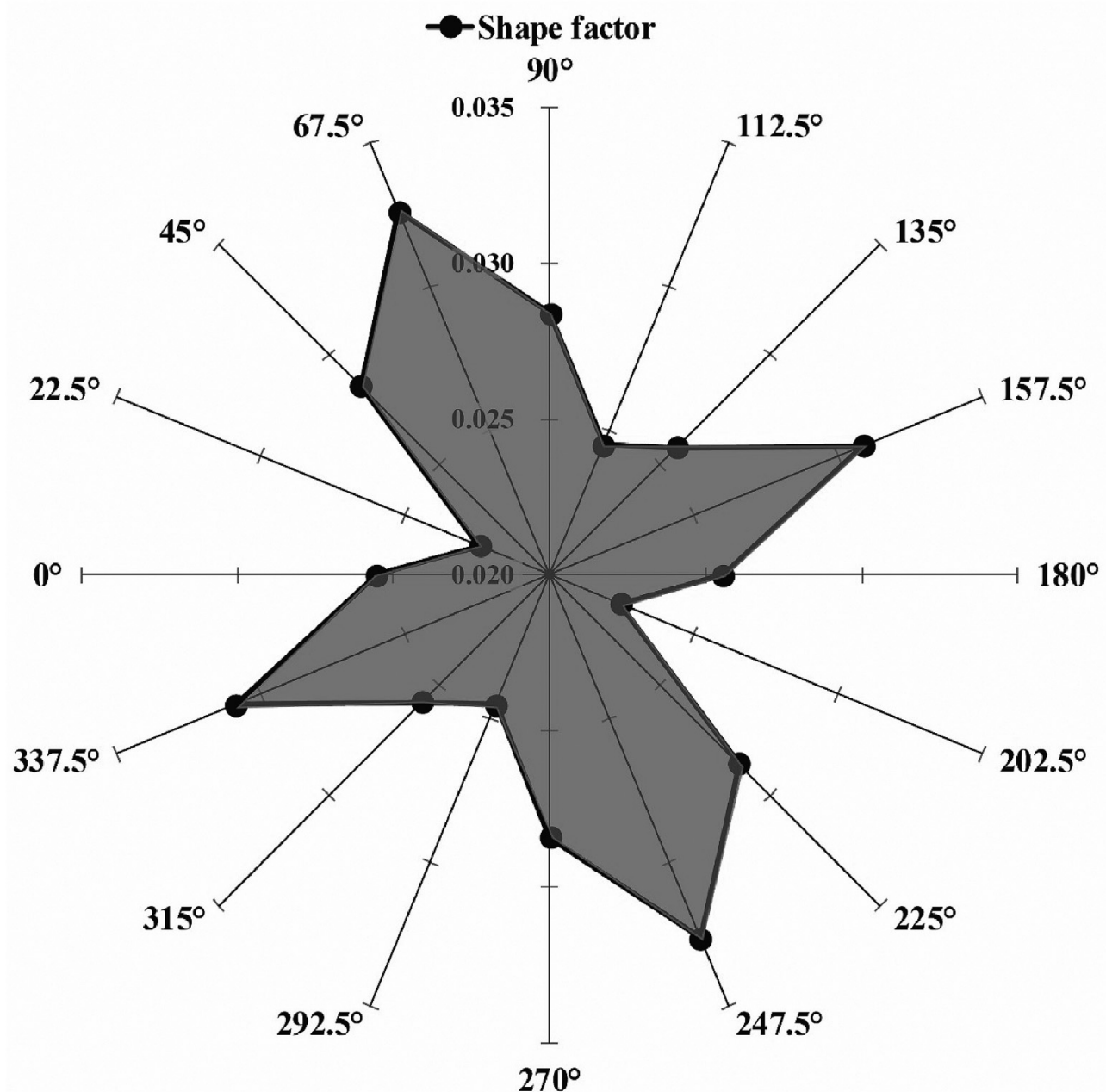

Fig. 4. The average "shape factor" in eight thin sections with different angles. 
long axis of the ellipse was calculated and used as the extension angle of the pores. Then, we calculated the standard deviation (mean square deviation) of all extension angles. Eight reservoir slices were calculated and eight standard deviations were plotted.

Here we referred to the standard deviation of the extended angle of the pore as the pore dispersion. The greater the dispersion, the less probability the formation of high permeability zones and the lower the recovery degree of remaining oil and gas. Conversely, the smaller the dispersion, the easier the formation of the dominant seepage zone and the higher the recovery degree of remaining oil and gas.

Fig. 5 shows that the maximum pore dispersion occurred at $112.5^{\circ}\left(292.5^{\circ}\right)$ and the minimum occurred at $22.5^{\circ}\left(202.5^{\circ}\right)$. This shows that the direction of $112.5^{\circ}\left(292.5^{\circ}\right)$ had the worst directionality and that it is not easy to form high permeability zones, and that it had the lowest the recovery degree of remaining oil and gas. The direction of $22.5^{\circ}\left(202.5^{\circ}\right)$ had the best directionality, which is easy to form high permeability zones, resulting in lower sweep degree in other directions, making the remaining oil and gas recoverable. The sharp angle of the reservoir slices where the two extreme values were located was $90^{\circ}$.

\subsection{The average pore-throat tortuosity}

Pore-throat tortuosity is the ratio of the actual length of the seepage channels and the apparent length the fluids flow through the seepage medium (the macro distance). Fluid particles flow through the medium in unit distance-the actual length of the motion trajectory of the particle. This is an important parameter for evaluation of the complexity of the seepage channel, and also one of the most important in the prediction of reservoir permeability [27].

Importantly, calculation of tortuosity should be based on its original definition. The perimeter of a single pore boundary should be calculated as the actual flow distance. Then, the Legendre ellipse fitting of a single pore should be carried out to obtain its equivalent long axis as its theoretical flow length. The tortuosity of a single pore can then be obtained by dividing the perimeter by the long axis. After calculating the pore-throat tortuosity of all single pores in a slice, the average value is calculated and the average value of the Pore-throat tortuosity of each slice is obtained.

Pore-throat tortuosity can directly indicate the curvature of the pore boundary. According to the principle of sedimentology, after weathering, denudation, transportation, and deposition, roughness of the pore boundary of the mineral particles that make up the

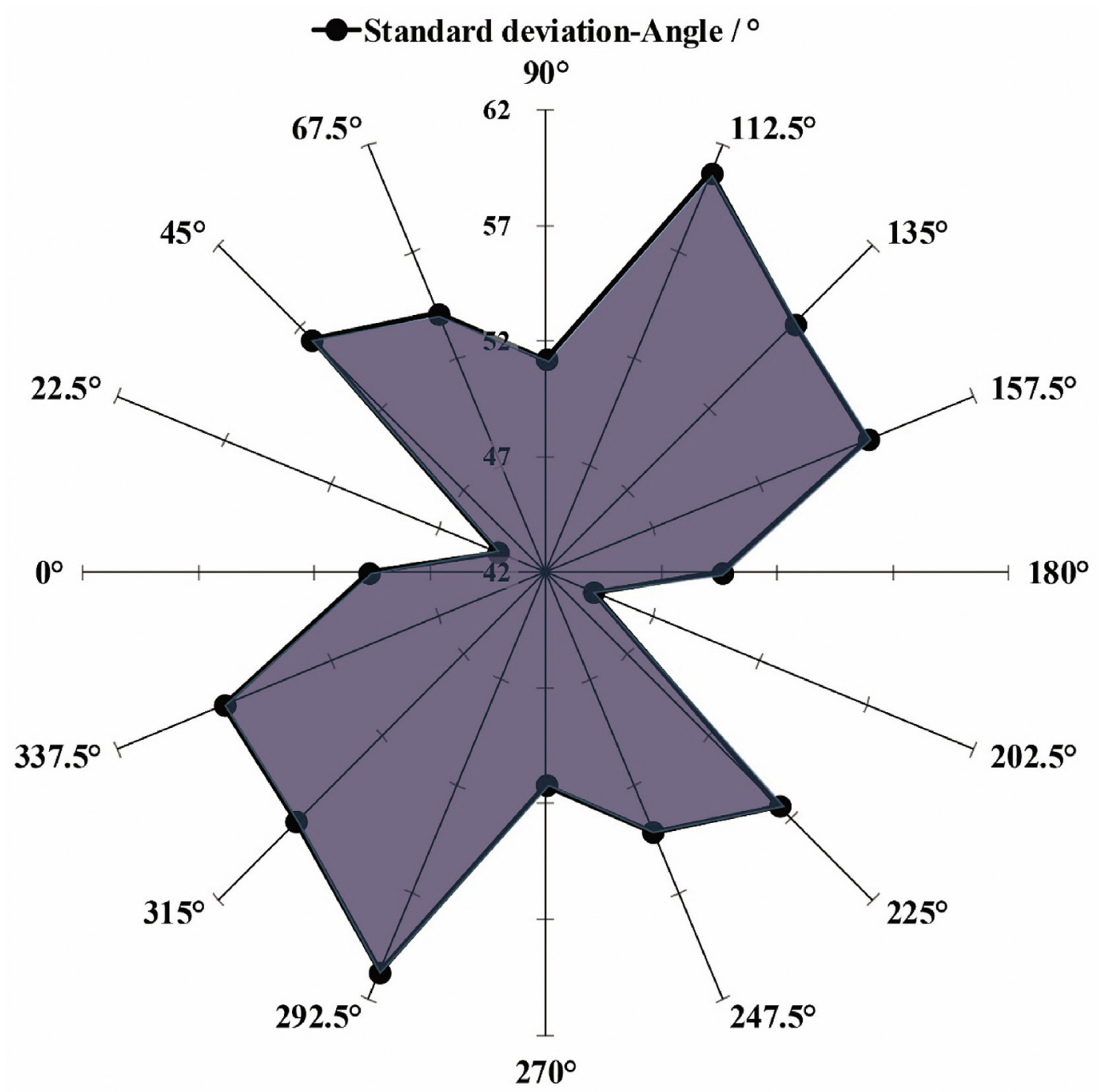

Fig. 5. The standard deviation of the average "extended angle" in eight thin sections with different angles. 
shale oil reservoir in the study area should be low in theory, because they have undergone a long period of transportation, separation, and rounding. The boundary should be relatively smooth and it should have a smoother curve.

The study of classical petroleum geology may be used to frame discussions of what causes the pore boundary to become rough. We know that when corrosion occurs, the boundary will be changed irregularly and the pore boundary will become rough. There may be two possible mechanisms, including the compaction differential corrosion mechanism and the dominant channel transport mechanism, which together control the geometry of pore boundary. Therefore, the geometric shape of the pore boundary is the result of competition between these two mechanisms.

\subsubsection{The first possible mechanism: the differential corrosion due to compaction process}

Pressure solution, also known as corrosion creep, is a plastic deformation process involving fluid in sedimentary rocks. Due to the action of pressure, some grains (usually calcite or quartz) in sedimentary rocks dissolve in the high-pressure stress zone, migrate through fluid, and precipitate in the low-pressure stress zone, resulting in plastic deformation.

The processes of vertical compaction and stress extrusion or stress tension are varied in different angles, resulting in the differences in degree of compaction and pressure corrosion in different angles, which is related to the mineral type, content, and primary pore development degree in each direction. When the pressure solution is strong, it is easy to transform the original smooth pore boundary into a curved pore boundary, thus increasing the tortuosity of the pore.

\subsubsection{The second possible mechanism: the seepage process} controlled by dominant channels

Geological fluid transport also has orientability, which is easy to cause varied corrosion in different directions. For example, the flow of acidic fluids along some directions will result in stronger corrosion in these directions, resulting in curved pore boundary and large pore-throat tortuosity, causing low corrosion in other directions and small pore-throat tortuosity.

Fig. 6 shows that the maximum value of the pore-throat solidity curve appeared at $112.5^{\circ}\left(292.5^{\circ}\right)$, and was much larger than the other values. The minimum value appeared at $45^{\circ}\left(225^{\circ}\right)$. This shows that the highest degree of corrosion was in the direction of $122.5^{\circ}\left(202.5^{\circ}\right)$, while the lowest was in the direction of $45^{\circ}\left(225^{\circ}\right)$. The sharp angle between the two extreme values was $67.5^{\circ}$.

Fig. 6 also shows that the maximum uniformity (sorting degree) of pore-throat tortuosity was $112.5^{\circ}\left(292.5^{\circ}\right)$ while the minimum was $157.5^{\circ}\left(337.5^{\circ}\right)$. This shows that the highest degree of corrosion would often make the distribution of corrosion uneven. The sharp angle between the two extremes was $45^{\circ}$.

Apparently, discussions regarding the level of significance that the first and second possible mechanism play on the corrosion degree of pores need to be performed respectively. We explored this problem by plotting the mean values of pore-throat solidity, the mean square deviations of pore-throat solidity, and the mean square deviations of pore extension angles with the tortuosities of pores.

Fig. 7 shows that the degree of corrosion decreased logarithmically with the decrease of compaction degree (pore-throat solidity increases gradually), and increased logarithmically with the decrease of compaction homogeneity degree (pore-throat solidity standard deviation increases). This shows that the external force (including three-dimensional stress) compaction has a significant role in promoting corrosion.

Meanwhile, the more heterogeneous the compaction, the higher the corrosion degree. This is explained by the principles of sedimentology and diagenesis. It also shows that the differential corrosion mechanism of compaction is important in controlling the degree of corrosion for tight reservoirs in the study area.

Similarly, Fig. 8 shows that the relationship between pore orientation (dominant seepage channel development) and corrosion is not obvious, which indicates that the relationship between them is not clear and needs further study. It shows that there is a linear relationship between the degree of compaction uniformity and the degree of corrosion uniformity. The more uniform the degree of compaction, the more uniform the degree of corrosion. This also provides evidence for the dominance of the corrosion mechanism of compaction difference.

\subsection{Pore-throat fractal dimension}

According to fractal theory, fractal dimension can be used as a
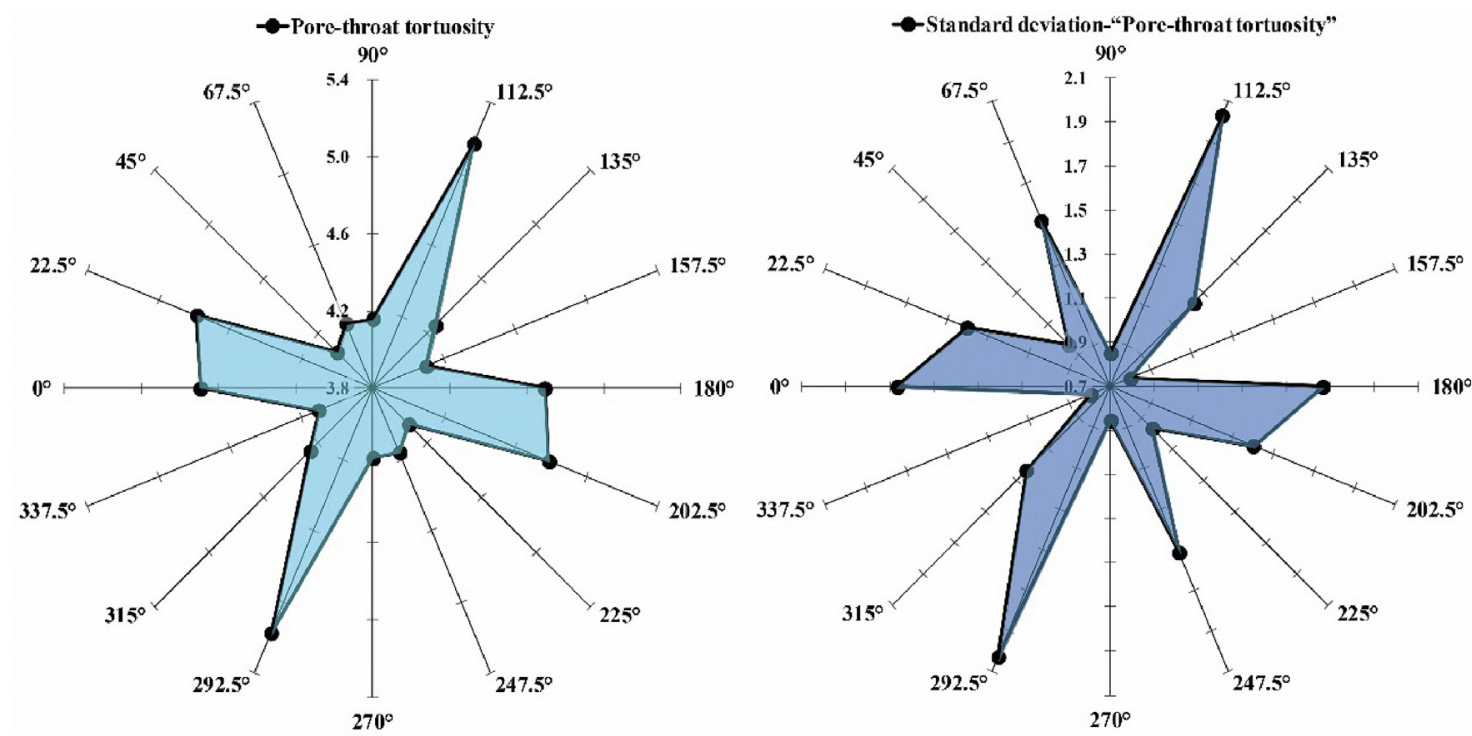

Fig. 6. The average and the standard deviation of "pore-throat tortuosity" in eight thin sections with different angles. 

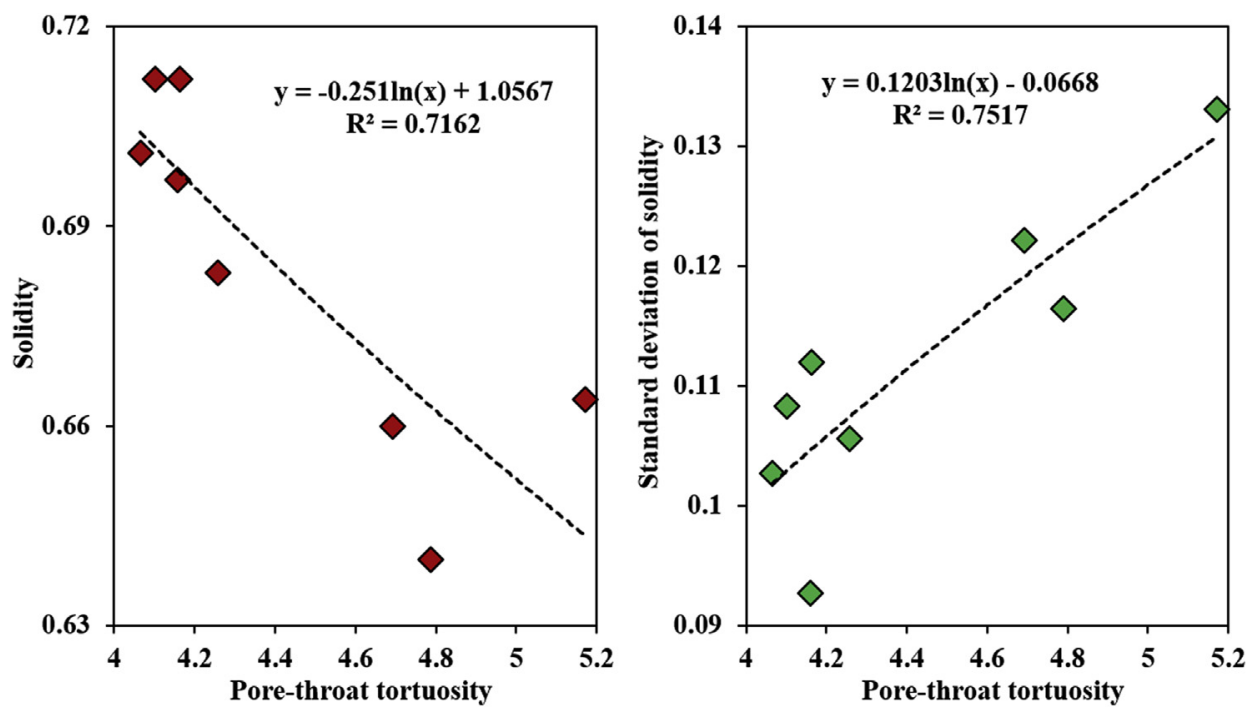

Fig. 7. The correlation between the degree of corrosion and the degree of absolute compaction, compaction uniformity.
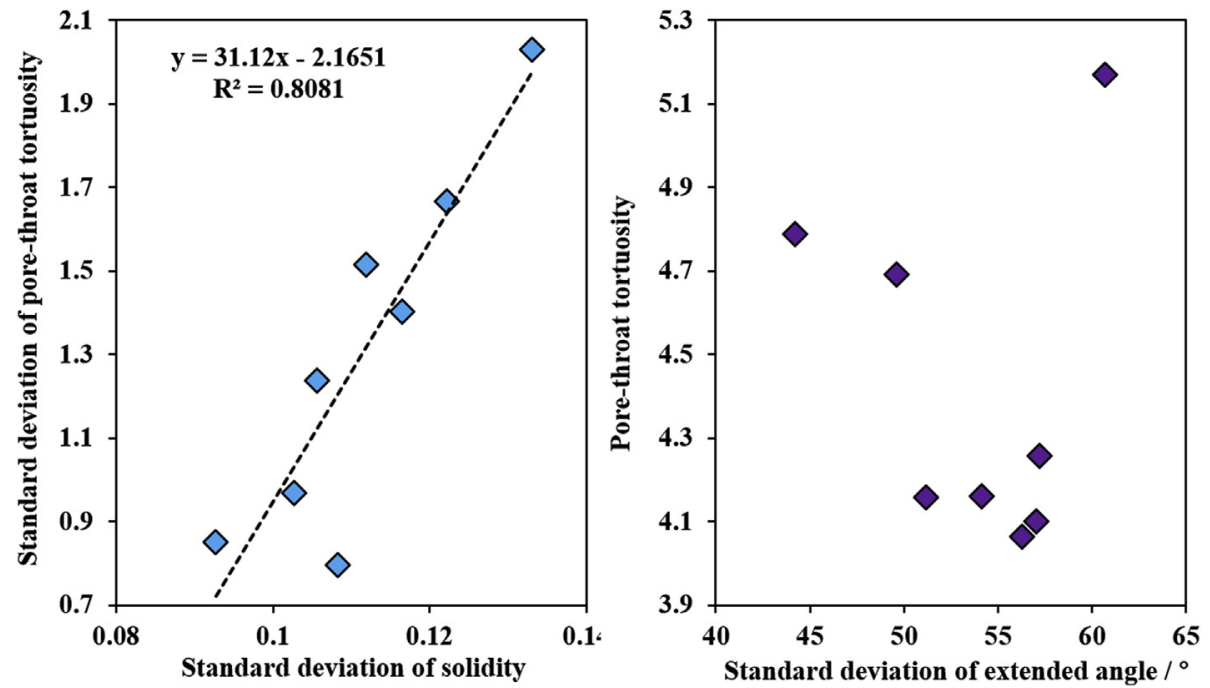

Fig. 8. The correlation between orientability of pores and degrees of corrosion.

comprehensive parameter to describe the complexity of geometric form. The larger the fractal dimension, the higher the complexity of representative form. The fractal dimension of pores in eight directions of reservoir slices was calculated and the change curve was drawn. The fractal dimension was calculated by the box counting method.

Fig. 9 shows that the maximum fractal dimension appeared at $0^{\circ}\left(180^{\circ} / 360^{\circ}\right)$ and the minimum appeared at $90^{\circ}\left(270^{\circ}\right)$. This shows that the development complexity of pores in $0^{\circ}\left(180^{\circ} / 360^{\circ}\right)$ direction was the highest, while that in the $90^{\circ}\left(270^{\circ}\right)$ direction was the lowest. The sharp angle between the two extreme values was $90^{\circ}$.

We studied all the parameters and their extended parameters separately and obtained a series of conclusions. Next, we used statistics on the extremes (including maximum and minimum) of all parameters and parameters standard deviations as well as their angles (that is, the angle between the direction of reservoir slice where the maximum of each parameter was located and the direction of the reservoir slice where the minimum of each parameter was located), so as to find the characteristics and rules of their mutual responses.

As shown in Table 1, for some parameters or their standard deviations, when their maximum or minimum values appeared on reservoir slices in the same direction, we believed that there was "affinity" between these parameters, and the main geological factors which controlled those parameters were closely related or even the same. Therefore, we arrived at the following conclusions:

(1) The maximum values of porosity, pore fractal dimension, and standard deviation of pore shape factor were all distributed at $0^{\circ}\left(180^{\circ} / 360^{\circ}\right)$. This shows that for reservoirs in the study area, the highest total development degree of pore often occurs simultaneously with the highest complexity of pore development, and the most uneven distribution of pore roundness, which has good affinity.

(2) The minimum values of permeability, pore-throat solidity, and pore shape factor are all distributed at $22.5^{\circ}\left(202.5^{\circ}\right)$. This shows that for the reservoirs in the study area, the 


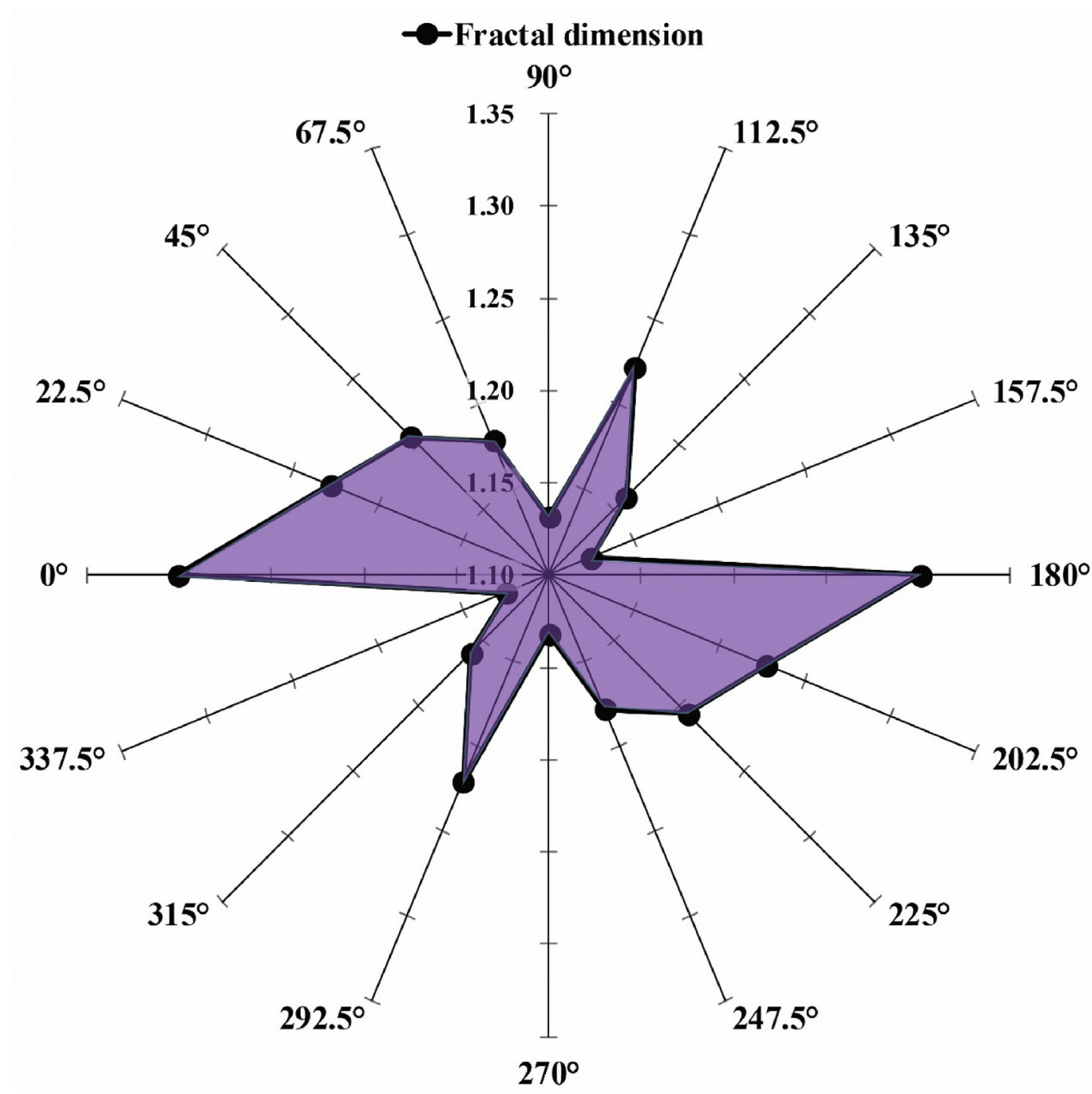

Fig. 9. The average "fractal dimension" in eight thin sections with different angles.

Table 1

Statistics of the maximum and minimum of all parameters.

\begin{tabular}{|c|c|c|c|c|c|c|c|}
\hline \multicolumn{2}{|c|}{ Parameters|Values } & \multirow{2}{*}{$\begin{array}{l}\text { Maximum } \\
0^{\circ}\left(180^{\circ} / 360^{\circ}\right)\end{array}$} & \multirow{2}{*}{$\begin{array}{l}\text { Maximum(standard } \\
\text { deviation) }\end{array}$} & \multirow{2}{*}{$\begin{array}{l}\text { Minimum } \\
135^{\circ}\left(315^{\circ}\right)\end{array}$} & \multirow{2}{*}{$\begin{array}{l}\text { Minimum(standard } \\
\text { deviation) }\end{array}$} & \multirow{2}{*}{$\begin{array}{l}\text { Minimum of } \\
\text { Intersection angle/ } \\
\\
135\end{array}$} & \multirow{2}{*}{$\begin{array}{l}\text { Minimum of Intersection } \\
\text { angle(standard deviation) } /^{\circ}\end{array}$} \\
\hline Porosity & & & & & & & \\
\hline Permeability & & $45^{\circ}\left(225^{\circ}\right)$ & & $22.5^{\circ}\left(202.5^{\circ}\right)$ & & 22.5 & \\
\hline $\begin{array}{l}\text { Pore-throat } \\
\text { solidity }\end{array}$ & $\begin{array}{l}\text { Standard deviation of pore- } \\
\text { throat solidity }\end{array}$ & $67.5^{\circ}\left(247.5^{\circ}\right)$ & $112.5^{\circ}\left(292.5^{\circ}\right)$ & $22.5^{\circ}\left(202.5^{\circ}\right)$ & $90^{\circ}\left(270^{\circ}\right)$ & 45 & 22.5 \\
\hline $\begin{array}{l}\text { Pore-throat } \\
\text { shape } \\
\text { factor }\end{array}$ & $\begin{array}{l}\text { Standard deviation of pore- } \\
\text { throat shape factor }\end{array}$ & $67.5^{\circ}\left(247.5^{\circ}\right)$ & $0^{\circ}\left(180^{\circ} / 360^{\circ}\right)$ & $22.5^{\circ}\left(202.5^{\circ}\right)$ & $135^{\circ}\left(315^{\circ}\right)$ & 45 & 45 \\
\hline \multicolumn{2}{|c|}{$\begin{array}{l}\text { Standard deviation of pore-throat } \\
\text { extended angle }\end{array}$} & & $112.5^{\circ}\left(292.5^{\circ}\right)$ & & $22.5^{\circ}\left(202.5^{\circ}\right)$ & & 90 \\
\hline $\begin{array}{l}\text { Pore-throat } \\
\text { tortuosity }\end{array}$ & $\begin{array}{l}\text { Standard deviation of pore- } \\
\text { throat tortuosity }\end{array}$ & $112.5^{\circ}\left(292.5^{\circ}\right)$ & $112.5^{\circ}\left(292.5^{\circ}\right)$ & $45^{\circ}\left(225^{\circ}\right)$ & $157.5^{\circ}\left(337.5^{\circ}\right)$ & 67.5 & 45 \\
\hline Fractal dimen & sion of pore-throat & $0^{\circ}\left(180^{\circ} / 360^{\circ}\right)$ & & $90^{\circ}\left(270^{\circ}\right)$ & & 90 & \\
\hline
\end{tabular}

weakest seepage capacity is often associated with the lowest compaction degree and the lowest pore roundness. In addition, the relationship between pore-throat orientation and reservoir permeability needs further exploration and discussion.
(3) The maximum permeability and the minimum pore-throat tortuosity are all distributed at $45^{\circ}\left(225^{\circ}\right)$. This shows that for the reservoirs in the study area, the weakest seepage ability often occurs at the same time with the lowest degree of corrosion, and has a good affinity. 
(4) The maximum values of pore-throat solidity and pore shape factor were $67.5^{\circ}\left(247.5^{\circ}\right)$. This shows that for reservoirs in the study area, the lowest degree of compaction often occurs at the same time as the highest pore roundness, which has a good affinity.

(5) The minimum of standard deviation of pore-throat solidity, and the minimum of fractal dimension are all distributed at $90^{\circ}\left(270^{\circ}\right)$. This shows that for reservoirs in the study area, the lowest uniform extent of compaction degree is closely related to the lowest pore complexity.

(6) The maximum of standard deviation of pore-throat solidity, the maximum of standard deviation of pore extension angle, the maximum of standard deviation of pore-throat tortuosity, and the maximum of pore-throat tortuosity are all distributed at $112.5^{\circ}\left(292.5^{\circ}\right)$. This shows that for reservoirs in the study area, the most heterogeneous degree of compaction often occurs simultaneously with the worst orientation of pore, the highest degree of corrosion, and the most non-homogeneous degree of corrosion, and has a good affinity.

(7) The minimum of porosity and the minimum of standard deviation of pore shape factor are all distributed at $135^{\circ}$ $\left(315^{\circ}\right)$. This shows that for reservoirs in the study area, the lowest total development of pores often occurs at the same time as the most uniform distribution of pore roundness, which has a good affinity. (8) The minimum standard deviation of the pore-throat tortuosity is $157.5^{\circ}\left(337.5^{\circ}\right)$. It is known that for each characterization parameter, its maximum and minimum must be distributed on reservoir slices in two directions, so the angle between the two directions (acute angle) is of interest.

It is believed that the magnitude of this angle can indicate the probability of mutation of each kind of parameter value. This is because the smaller the angle, the smaller the slice spacing between the maximum and minimum values. This means if the probability of mutation of the parameter is small, and the factor controlling the value of the parameter would be single. That is to say, when one of the factors changes, the parameter can also change. On the contrary, if the angle is (the interval between the maximum and minimum) is large, and the probability of sudden change of the parameter is small, the dominant factors of the parameter value are not single. That is to say, when one of the factors changes, there will be no obvious change in the parameter. Only when all the factors change at the same time, will the parameter change at the same time.

From Table 1, the following implications are noted:

(1) For the standard deviation of permeability and pore-throat solidity, the angle between the extreme values was $22.5^{\circ}$.

(2) For the standard deviation of porosity, pore-throat solidity, pore shape factor, pore shape factor, pore shape factor, and pore-throat tortuosity, the angle between the extreme values was $45^{\circ}$.

(3) For the standard deviation of pore-throat tortuosity, the angle between the extreme values was $67.5^{\circ}$.

(4) For fractal dimension and standard deviation of the pore extension angle, the angle between the extreme values was $90^{\circ}$.

\section{Conclusion}

As the various properties of reservoirs are the results of the coupling of multiple geological processes, characteristics of the single geological process would vary in different directions, such as compaction, fluid filling, corrosion, diagenesis, etc. Therefore, when there are extreme points of reservoir properties, that also means the trend of the property change reverses after some points.

It can be concluded that there is an obvious intensity conversion zone of the geological process at the extreme points. The greater the curvature of the changing curve composed of the extreme point and its front and back points, the higher and faster the intensive conversion of the geological process.

Additionally, since standard deviation is the most commonly used quantitative form to reflect the degree of discreteness of a group of data, its numerical value holds significant geological indicators; that is, it can reflect the degree of sorting degrees of a reservoir property. Therefore, we calculated the standard deviation of each property in each slice and plotted the curve of the standard deviation of each property in each slice changing with the angle. These curves characterized the heterogeneity of reservoirs from different angles.

Since 2018, the author of this paper and his colleagues have published a series of research results on the basic principle, technical details, case analysis and application scope of "Umbrella Deconstruction" method. However, we need to be clear that there are still many questions that remain ambiguous on "Umbrella Deconstruction" method. The existing operation process is suitable for solving most of the scientific problems in reservoir rocks, but it cannot solve all of them. With the diversity of research objects and the increasing complexity of their reservoir space, elements and minerals, many technical details of "Umbrella Deconstruction" method need to be further improved. For example, there are still many problems in the study of the accurate characterization of pore heterogeneity. Further research is needed to solve the contradiction between observation resolution and sample scale. In addition, with the development of research objectives, "Umbrella Deconstruction" method can be combined with a variety of new technologies to form the new combination technology to achieve our research objectives. This is a crucial area of research and focus of future efforts, which reserves care attention.

\section{Author contribution}

Shuheng Du, Conceptualization, Methodology, Writing - original draft preparation, Funding acquisition, Data curation, Writing original draft preparation Supervision.

\section{Declaration of competing interest}

The authors declare that they have no known competing financial interests or personal relationships that could have appeared to influence the work reported in this paper.

\section{Acknowledgements}

This work was jointly supported by National Natural Science Foundation of China (NSFC, Grant No.41902132, 11872363, 51861145314), PetroChina Innovation Foundation (Grant No.2019D5007-0214), Chinese Academy of Sciences (CAS) through the CAS Key Research Program of Frontier Sciences (Grant No. QYZDJ-SSWJSC019) and the CAS Strategic Priority Research Program (Grant No. XDB22040401). Thanks very much for the recognition by the editor and the reviewers of the journal.

\section{Appendix A. Supplementary data}

Supplementary data to this article can be found online at https://doi.org/10.1016/j.energy.2020.118630. 


\section{References}

[1] Zhao YP. Modern continuum mechanics. Beijing, China: Science Press; 2016.

[2] Zhao YP. Lectures on mechanics, beijing. China: Science Press; 2018.

[3] Qiao W, Huang K, Azimi M, Han S. A novel hybrid prediction model for hourly gas consumption in supply side based on improved whale optimization algorithm and relevance vector machine. IEEE Access 2019;7:88218-30.

[4] Jia A, Wei Y, Liu C, Wang J, Qi Y, Jia C, Li B. A dynamic prediction model of pressure-control production performance of shale gas fractured horizontal wells and its application. Nat Gas Ind B 2020;7(1):71-81.

[5] Azadeh A, Tarverdian S. Integration of genetic algorithm, computer simulation and design of experiments for forecasting electrical energy consumption. Energy Pol 2007;35(10):5229-41.

[6] Aydin G. Production modeling in the oil and natural gas industry: an application of trend analysis. Petrol Sci Technol 2014;32(5):555-64.

[7] Meunier F. The greenhouse effect: a new source of energy. Appl Therm Eng 2007;27(2-3):658-64.

[8] BP Statistical Review of World Energy. https://www.bp.com/en/global/ corporate/energy-economics/statistical-review-of-world-energy.html. [Accessed June 2019].

[9] Du S, Xu F, Taskyn A, Zhou B, Kou G, Shi Y. Anisotropy characteristics of element composition in Upper Triassic "Chang 8" shale in Jiyuan district of Ordos Basin, China: microscopic evidence for the existence of predominant fracture zone. Fuel 2019a;253:685-90.

[10] Xiao K, Li H, Duan Y, Zhang Y, Liu L. Reservoir characteristics and main controlling factors of the Leikoupo gas pools in the western Sichuan Basin. Nat Gas Ind B 2020;7(1):13-23.

[11] Gunde AC, Bera B, Mitra SK. Investigation of water and CO2 (carbon dioxide) flooding using micro-CT (micro-computed tomography) images of Berea sandstone core using finite element simulations. Energy 2010;35(12): 5209-16.

[12] Klaver J, Desbois G, Urai JL, Littke R. BIB-SEM study of the pore space morphology in early mature Posidonia Shale from the Hils area, Germany. Int J Coal Geol 2012;103:12-25.

[13] Lai P, Krevor S. Pore scale heterogeneity in the mineral distribution and surface area of Berea sandstone. Energy Procedia 2014;63:3582-8.

[14] Alyafei N, Mckay TJ, Solling TI. Characterization of petrophysical properties using pore-network and lattice-Boltzmann modelling: choice of method and image sub-volume size. J Petrol Sci Eng 2016;145:256-65.

[15] Lewis RT, Seland JG. A multi-dimensional experiment for characterization of pore structure heterogeneity using NMR. J Magn Reson 2016;263:19-32.

[16] Wang P, Jiang Z, Ji W, Zhang C, Yuan Y, Chen L, Yin L. Heterogeneity of intergranular, intraparticle and organic pores in Longmaxi shale in Sichuan Basin, South China: evidence from SEM digital images and fractal and multifractal geometries. Mar Petrol Geol 2016;72:122-38.
[17] Huang W, Lu S, Hersi OS, Wang M, Deng S, Lu R. Reservoir spaces in tight sandstones: classification, fractal characters, and heterogeneity. J Nat Gas Sci Eng 2017;46:80-92.

[18] Jin L, Hawthorne S, Sorensen J, Pekot L, Kurz B, Smith S, Heebink L, Herdegen V, Bosshart N, Torres J, Dalkhaa C, Peterson K, Gorecki C, Steadman E, Harju J. Advancing CO2 enhanced oil recovery and storage in unconventional oil play-experimental studies on Bakken shales. Appl Energy 2017;208:171-83.

[19] Saif T, Lin Q Butcher AR, Bijeljic B, Blunt MJ. Multi-scale multi-dimensional microstructure imaging of oil shale pyrolysis using X-ray microtomography, automated ultra-high resolution SEM, MAPS Mineralogy and FIB-SEM. Appl Energy 2017;202:628-47.

[20] Munawar MJ, Lin C, Cnudde V, Bultreys T, Dong C, Zhang X, Boever WD, Zahid MA, Wu Y. Petrographic characterization to build an accurate rock model using micro-CT: case study on low-permeable to tight turbidite sandstone from Eocene Shahejie Formation. Micron 2018;109:22-33.

[21] Sun Y, Zhao Y, Yuan L. Quantifying nano-pore heterogeneity and anisotropy in gas shale by synchrotron radiation nano-CT. Microporous Mesoporous Mater 2018;258:8-16.

[22] Du S, Pang S, Shi Y. Quantitative characterization on the microscopic pore heterogeneity of tight oil sandstone reservoir by considering both the resolution and representativeness. J Petrol Sci Eng 2018a;169:388-92.

[23] Du S, Pang S, Shi Y. A new and more precise experiment method for characterizing the mineralogical heterogeneity of unconventional hydrocarbon reservoirs. Fuel 2018b;232:666-71.

[24] Du S, Zhao Y, Jin J, Kou G, Shi Y, Huang X. Significance of the secondary pores in perthite for oil storage and flow in tight sandstone reservoir. Mar Petrol Geol 2019b;110:178-88.

[25] Du S, Shi Y, Zheng X, Chai G. Using "Umbrella Deconstruction \& Energy Dispersive Spectrometer (UD-EDS)" technique to quantify the anisotropic elements distribution of" Chang 7" shale and its significance. Energy 2020a; 191:116443.

[26] Du S, Pang S, Chai G, Wang H, Shi Y. Quantitative analysis on the microscopic anisotropy characteristics of pore and mineral in tight reservoir by "umbrella deconstruction" method. Earth Sci 2020b;45(1):276-84 [in Chinese)].

[27] Du S. Characteristics and the formation mechanism of the heterogeneous microfractures in the tight oil reservoir of Ordos Basin, China. J Petrol Sci Eng 2020;191:107176.

[28] Chen J, Peng H, Fan J, Zhang X, Liu W, Jiang D. Microscopic investigations on the healing and softening of damaged salt by uniaxial deformation from CT, SEM and NMR: effect of fluids (brine and oil). RSC Adv 2020:10(5):2877-86.

[29] Shi GX, Kou G, Du SH, Wei Y, Zhou W, Zhou B, Li Q, Wang B, Guo HY, Lou QX, $\mathrm{Li}$ T. What role would the pores related to brittle minerals play in the process of oil migration and oil \& water two-phase imbibition? Energy Rep 2020c;6: $1213-23$. 